\title{
Health benefits of orally administered anti-IL-10 antibody in milk-fed dairy calves
}

\author{
S. M. Raabis, ${ }^{*}$ T. L. Ollivett, ${ }^{*}$ M. E. Cook, $†$ J. M. Sand, $†$ and S. M. McGuirk*1 \\ ${ }^{*}$ Department of Medical Sciences, School of Veterinary Medicine, and \\ †Department of Animal Science, University of Wisconsin, Madison 53706
}

\begin{abstract}
The primary objective of this randomized controlled trial was to determine whether anti-IL-10 egg yolk antibodies fed upon arrival to a calf ranch would lower the prevalence of Cryptosporidium parvum shedding in naturally challenged preweaned dairy calves. The secondary objectives included measuring the effect of anti-IL-10 antibodies on calf health, performance, and shedding of less common diarrheal pathogens. A total of 133 calves, enrolled at 24 to $72 \mathrm{~h}$ of age, received a daily dose of $0.96 \mathrm{~g}$ of egg yolk powder with antiIL-10 antibodies (MAB, $\mathrm{n}=71$ ) or without anti-IL-10 antibodies (MEP, $\mathrm{n}=62$ ) split between 2 feedings for the first $11 \mathrm{~d}$ on feed at a calf ranch. Daily health evaluations were completed for $15 \mathrm{~d}$ after arrival and on d 56. Digital weights were collected at enrollment and d 56 , and hipometer weights were collected at enrollment and d 7 and 56. Packed cell volume and serum total protein concentration were measured at enrollment and on $\mathrm{d} 7$ and 14 . Fecal $\mathrm{pH}$ was measured at enrollment and on $\mathrm{d} 5$ and 14, and fecal pathogen (C. parvum, coronavirus, rotavirus, and Salmonella spp.) shedding was assessed at $\mathrm{d} 5$ and 14 . Continuous outcomes were compared between groups using a Student's $t$-test or Wilcoxon rank sum test. Fecal pathogen shedding at $\mathrm{d} 14$, respiratory disease at $\mathrm{d} 56$, and antibiotic usage were compared using relative risk $(\mathrm{RR})$ and chi-squared test. Fecal $\mathrm{pH}$ (median and interquartile range) on $\mathrm{d}$ 14 was 6.65 (6.39-6.99) and 6.52 (5.97-6.81) for MAB and MEP, respectively. On d 56, the risk of respiratory disease was lower for MAB compared with MEP (RR = 0.40 ; confidence interval $=0.16-0.99)$. The risk for antibiotic treatment was lower for MAB- compared with MEP-treated calves $(\mathrm{RR}=0.38$; confidence interval $=$ 0.17-0.88). The risk of shedding rotavirus was higher in $\mathrm{MAB}(\mathrm{RR}=1.38$; confidence interval $=1.10-1.81$ ) calves. After multivariable analyses, hipometer weights
\end{abstract}

Received December 11, 2017.

Accepted April 6, 2018.

${ }^{1}$ Corresponding author: sheila.mcguirk@wisc.edu (least squares means \pm standard error) were $1.7 \pm 0.8 \mathrm{~kg}$ greater on d 56 in MAB compared with MEP; however, ADG was $0.04 \pm 0.02 \mathrm{~kg} / \mathrm{d}$ lower in MAB calves. Total health score, diarrhea days, average respiratory score, packed cell volume, and serum total protein were not affected by feeding anti-IL-10 egg antibodies. In summary, feeding anti-IL-10 antibodies was associated with increased fecal $\mathrm{pH}$, reduced risk of respiratory disease later in the preweaning period, and decreased antibiotic usage despite higher rotavirus infection. These findings might be associated with improved mucosal immunity, enhanced host defenses, or reduced susceptibility and warrant further investigation.

Key words: Cryptosporidium parvum, fecal pH, bovine respiratory disease, antibiotic alternative, neonatal calf diarrhea

\section{INTRODUCTION}

Neonatal calf diarrhea (NCD) and bovine respiratory disease (BRD) are the most common causes of morbidity and mortality in preweaned dairy calves (Windeyer et al., 2014; Cramer and Stanton, 2015). Although NCD and BRD may be independent events affecting calves before weaning, the risk of BRD is increased in calves that have had other disease problems such as NCD in the first 2-wk of life (Windeyer et al., 2014). Effective prevention, detection, and treatment are paramount for controlling NCD and, therefore, $\mathrm{BRD}$, but the development of farm protocols is challenging because of the mixed array of causative organisms (viral, bacterial, or parasitic), the prevalence of mixed infections, and the potential role of nutrition. Cryptosporidium parvum, rotavirus, coronavirus, and Salmonella spp. are important enteropathogens of 5- to 14-d-old calves (McGuirk, 2008). Treatment is challenging because approved antimicrobial drugs have questionable efficacy (Smith, 2015) and antibiotic use may increase emergence of resistant bacteria (Berge et al., 2006). With few effective treatment and prevention options, passive transfer of the maternal antibody remains a mainstay in managing NCD. However, recent 
studies have provided evidence for the effectiveness of egg yolk-derived antibody protection against diarrhea (Yokoyama et al., 1998; Mine and Kovacs-Nolan, 2002; Vega et al., 2011; Diraviyam et al., 2014).

Egg yolk antibodies can target luminal contents or luminal receptors of specific pathogens, such as Salmonella Typhimurium and Salmonella Dublin; are not absorbed after gut closure (Vega et al., 2011); protect calves from disease (Yokoyama et al., 1998; Diraviyam et al., 2014); and pose no food safety concerns (Cook and Trott, 2010). Immunoglobulin Y (IgY), the major antibody in egg yolk, is functionally similar to mammalian IgG and economically feasible to produce in a noninvasive manner (Lee et al., 2012).

As a cause of NCD, protozoal infections due to $C$. parvum are particularly challenging because of the high prevalence of the organism, environmental persistence, and public health concerns (Nydam and Mohammed, 2005). In particular, C. parvum causes enterocyte changes resulting in diarrhea, dehydration, and abnormal gut fermentation in the large bowel, producing fecal acidity (Sato, 2010; Wyatt et al., 2010).

Recovery from C. parvum depends largely on the cytotoxic activities involved in a $\mathrm{T}$ helper 1 response (Weaver et al., 2000; Wyatt et al., 2010). More specifically, in calves recovering from C. parvum infection, IFN-gamma and $\operatorname{IgG}_{2}$ have been documented, signifying a $\mathrm{T}$ helper 1 response (Wyatt et al., 2001).

Research has shown that the protective $\mathrm{T}$ helper 1 immune response is suppressed by IL-10, an antiinflammatory cytokine produced by intraepithelial lymphocytes of calves infected with $C$. parvum (Wyatt et al., 2002). Interleukin-10 knockout mice are more resistant to C. parvum infection (Campbell et al., 2002), suggesting that Il-10 induction may prolong $C$. parvum infection and slow recovery. Provision of an oral antibody to IL-10 to broiler chickens infected with the coccidian parasite, Eimeria spp., eliminated growth depression (Sand et al., 2016). Therefore, the primary objective of this study was to determine whether antiIL-10 egg yolk antibodies fed upon arrival to a calf ranch would lower the fecal shedding of C. parvum in preweaned dairy calves after natural exposure. Our secondary objectives included measuring the effect of anti-IL-10 antibody on calf health, performance, fecal acidity, and shedding of less common diarrheal pathogens.

\section{MATERIALS AND METHODS}

\section{Animals and Experimental Groups}

This study was performed on a single calf-raising facility in southwest Wisconsin. A total of 134 calves from 12 source dairies were enrolled on $5 \mathrm{~d}$ over a $2 \mathrm{wk}$ period (July 29, 2014, through August 7, 2014) as they arrived at a calf-raising operation. Calves were 24 to 72 $\mathrm{h}$ of age on the day of enrollment and had been administered colostrum at their home farms. Male and female Holstein and Jersey calves were included. A random number generator was used on each enrollment day to randomize calves into 3 color-coded groups to receive a daily dose of $0.96 \mathrm{~g}$ of egg yolk powder with antiIL-10 antibodies (MAB: green and purple) or without anti-IL-10 antibodies (MEP: orange). Color-coded zip ties were attached to each outdoor hutch to ensure all calves received the correct dose. All calf feeders, health screeners, and farm personnel were blinded to the color code. This study was approved by the Research Animal Resource Center and the Animal Care and Use Committees in the School of Veterinary Medicine at the University of Wisconsin-Madison (Protocol: V01637).

\section{Calf Housing and Feeding Management}

Upon arrival calves were housed in indoor, individual pens with straw bedding in a naturally ventilated barn for 1 to $4 \mathrm{~d}$. Once calves were nursing well from a bottle, calves were moved to an individual, outdoor hutch, where they remained for the duration of the study. Calves were fed pasteurized waste milk by nipple bottle. Calves were fed $2 \mathrm{~L}$ twice per day at 12 -h intervals while in indoor housing. Once in the outdoor hutch, calves were fed $2 \mathrm{~L} 3$ times a day until $21 \mathrm{~d}$, when they were fed $3 \mathrm{~L}$ twice daily until $49 \mathrm{~d}$. At 49 d calves were fed $3 \mathrm{~L}$ once daily until d 56 , when they were weaned. Water and an $18 \%$ calf starter texturized feed was offered upon arrival to the outdoor calf hutch.

\section{Formulation of Anti-IL-10 Antibodies}

Single Comb White Leghorn laying hens raised for life in cages with raised wire were injected $(100 \mu \mathrm{g}$ of conjugate per chicken) with bovine IL-10-bovine gamma globulin-vmpqaenh conjugate emulsified with Freund's Complete Adjuvant at 1:1 vol/vol (Thermo Fisher Scientific Inc., Waltham, MA) for a total volume of $1 \mathrm{~mL}$ per chicken. The protein sequence VMPQAENH was used to conjugate to the carrier protein bovine gamma globulin. Sequence VMPQAENH is the portion of the IL-10 sequence that was used to make the antibody to IL-10 for use in dairy calves. This protein sequence was made at GenScript (Piscataway, NJ). Hens injected with adjuvant and bovine gamma globulin only (no peptide conjugate) were used for making control antibodies. Chickens were injected 1 wk later using the antigens described above. Eggs were collected begin- 
ning $3 \mathrm{wk}$ after the initial injection for a period of $8 \mathrm{wk}$. Egg yolks were separated from the albumen, lyophilized, and stored at room temperature until needed. Enzyme-linked immunosorbent assays were then used to determine the titer of the antibody.

\section{Experimental Design and Data Collection}

Calves in both experimental groups were administered $0.96 \mathrm{~g}$ of egg yolk powder per day divided into 2 of the 3 daily milk feedings (total dose: $1.2 \mathrm{~g} / \mathrm{kg}$ of $\mathrm{DM}$ ) for the first $11 \mathrm{~d}$ on feed, which was considered the major challenge period for the pathogens associated with NCD. The dried egg powder was mixed with water to make individual calf aliquots of $5 \mathrm{~mL}$ of egg yolk solution that was added to 2.8-L bottles of pasteurized whole milk twice daily from the day after enrollment (d 0) and through d 10 (total of $11 \mathrm{~d}$ ). The dose that was used was translated from the dose that had been previously effective in poultry and a small trial in postweaned steers (M. E. Cook and J. M. Sand, unpublished data).

Daily health screening was performed from $\mathrm{d} 0$ through 14 and again at weaning on d 56. Attitude, appetite, rectal temperature, ear position, ocular discharge, nasal discharge, presence of a spontaneous or inducible cough, umbilicus, joints, and fecal consistency were graded using a 0 (normal) to 3 (severe abnormality) system (McGuirk and Peek, 2014). Based on the results from this exam, a total health score was calculated for each calf. Calves with a respiratory score of 5 or higher were considered positive for respiratory disease, provided at least 2 clinical signs of respiratory disease (temperature, ear position, ocular discharge, nasal discharge, or cough) had scores of 2 or 3 (McGuirk and Peek, 2014). A cumulative health score for each treatment group was then calculated by summing the total health scores from all days for all of the calves within the same treatment group. Calves with fecal scores of 2 or 3 were considered positive for diarrhea. For the purposes of analysis, navel infection was defined as navel scores of 2 or 3. Farm staff were not provided the results of daily health screening.

Jugular blood was collected, using 20-gauge, 2.54-cm Vacutainer needles (Monoject Sherwood Medical Company, St. Louis, MO), into BD Vacutainer EDTA tubes (Becton, Dickinson and Company, Franklin Lakes, NJ) on d 0,7 , and 14 to monitor packed cell volume (PCV). On enrollment day, blood was collected into BD Vacutainer tubes without additive (Becton, Dickinson and Company) to measure serum total protein (STP) as a proxy for passive transfer of maternal antibody. Microhematocrit tubes (Thermo Fisher Scientific Inc.) Serum was collected after centrifugation at 11,269 $\times g$ at $23^{\circ} \mathrm{C}$ for 5 min (IEC MB Centrifuge, International Equipment Company, Nashville, TN), and STP was determined using a DD-1 Palm Abbe Digital Hand-Held Refractometer (Misco, Minneapolis, MN). Microhematocrit tubes (Thermo Fisher Scientific Inc.) were used to centrifuge whole blood at $11,269 \times g$ at $23^{\circ} \mathrm{C}$ for 5 min. The PCV was measured using a microhematocrit reader chart (VIN, Davis, CA), and plasma protein was determined using the DD-1 Palm Abbe Digital HandHeld Refractometer. Failure of passive transfer was defined as STP $<5.5 \mathrm{~g} / \mathrm{dL}$. Digital weights (kg; Optima Calf Scale OP 900B, Rancho Cucamonga, CA) were recorded on d 0 and 56 and used to calculate ADG. Hipometer-estimated weights were recorded on d 0,7 , 14, and 56. Hipometer weights were based on the width between the greater trochanters of the left and right femurs as previously described (Dingwell et al., 2006). Antibiotic usage by farm personnel was retrieved from farm computerized records at the end of the trial. Cost per calf was calculated by dividing the total cost of antibiotics used within the group by the total number of calves in each treatment group. Antibiotic costs were based on wholesale prices current during the time of the study.

Fecal samples were collected from each calf on d 0 , 5 , and 14; held at room temperature during transport before testing fecal $\mathrm{pH}(\mathrm{d} 0,5,15)$; and submitted for Salmonella spp. culture (d 5, 14) and multiplex reversetranscriptase PCR testing (d 5, 14). As a proxy for proper intestinal and colon function (Sato, 2010), fecal $\mathrm{pH}$ was measured after mixing $5 \mathrm{~mL}$ of feces with 15 $\mathrm{mL}$ of deionized water and directly placing the fecal solution on the sensor of a calibrated $\mathrm{pH}$ meter (Laqua Twin $\mathrm{pH}$ Meter, Horiba International Corporation, Kyoto, Japan).

Culturing for Salmonella spp. was performed by aseptically adding $1 \mathrm{~g}$ of feces to $10 \mathrm{~mL}$ of Rappaport Vassiliadis broth (Remel, Lenexa, KS) and to $9 \mathrm{~mL}$ of selenite broth (Remel). Both enrichment broths were incubated overnight at $35^{\circ} \mathrm{C}$, streaked onto XLT4 agar (Remel), and reincubated at $35^{\circ} \mathrm{C}$ for 24 to $48 \mathrm{~h}$. Presumptive black colonies of Salmonella spp. were isolated and identified biochemically using a semi-automated system according to the manufacturer's instructions (Vitek 2 Compact system, bioMérieux Inc., Hazelwood, MO). Serotypes for isolates identified as Salmonella spp. were determined by the Wisconsin Veterinary Diagnostic Laboratory (Madison, WI) according to the Kauffmann-White scheme using commercially available typing sera.

The C. parvum, rotavirus, and coronavirus multiplex reverse-transcriptase PCR testing (Cho et al., 2010) was also completed at the Wisconsin Veterinary Diagnostic Laboratory. Calves were considered positive 
for shedding of C. parvum, rotavirus, or coronavirus if the cycle-threshold value for that pathogen was less than 40, a cutoff determined by the Wisconsin Veterinary Diagnostic Laboratory. Cycle-threshold values of 37 to 40 indicate low amounts of target nucleic acid, which may represent early infection or environmental contamination.

\section{Statistical Analysis}

The sample size was driven by an expected reduction in the prevalence of $C$. parvum shedding (proportion testing positive) after naturally occurring exposure. Historically, approximately $40 \%$ of calves tested positive for fecal shedding at this calf ranch. A sample size of approximately 65 calves per group was selected based on clinical experience of the investigators (S. McGuirk, M. Cook, and J. Sand). Based on this sample size, we would need to see a difference of $25 \%$ to reach a power of 0.8 (Power procedure, SAS 9.4, SAS Institute Inc., Cary, NC). The authors felt that it was reasonable and achievable to reduce the prevalence of shedding from 40 to $15 \%$ based on previous experience using anti-IL-10 antibody in other species.

Continuous variable outcomes were visually assessed for normality using histograms. Variables that followed a normal distribution were compared using Student's $t$-test and included PCV, STP, and ADG. Comparisons between treatment groups for continuous variables that did not follow a normal distribution (fecal $\mathrm{pH}$, change in fecal $\mathrm{pH}$, fecal pathogen shedding, hipometer estimated weights, antibiotic costs, and cumulative health scores) were compared using the Wilcoxon rank sum test on $\mathrm{R}$ studio software version 1.0.44 (RStudio Inc., Boston, MA; http://www.rstudio.com/). The Wilcoxon rank sum test tests the null hypothesis that the outcome distributions do not differ between groups (Dickinson Gibbons and Chakraborti, 2003). When the distributions are the same, the Wilcoxon rank sum test acts as a test of medians.

Simple $2 \times 2$ contingency tables were created, and relative risks were calculated for fecal pathogen shedding on d 14 , respiratory disease at d 56, and antibiotic usage (medcalc.org). Comparisons between groups for the proportions of calves testing positive for diarrhea and clinical respiratory disease throughout the study period were assessed using chi-squared test.

Multivariable linear regression models (Mixed procedure, SAS 9.4) were fit to determine the effect of treatment on calf growth data (hipometer weight at arrival, hipometer weight at $\mathrm{d} 56$, the change in hipometer weight between arrival and d 56, and ADG). After univariable analysis, explanatory variables that resulted in $P \leq 0.20$ were included as fixed effects in the multivari- able model. Explanatory variables that were checked in the univariable analysis included calf sex (male or female), arrival weight (low $=$ hipometer weight below the median arrival weight; high $=$ hipometer weight at or above the median arrival weight), and navel infection (yes or no). Biologically plausible 2-way interactions were tested for significance. Manual backward stepwise elimination was used to reduce the model until all remaining variables were significant at the $\alpha \leq 0.05$ level. The final models were assessed graphically for outliers, influential observations, and normality using plots of fitted values versus Studentized residuals, Cook's distance, and leverage.

Multivariable logistic regression models (Glimmix procedure, SAS 9.4) were fit to determine the effect of treatment on the probability of respiratory disease at $\mathrm{d}$ 56 and antibiotic treatment. After univariable analysis, explanatory variables that resulted in $P \leq 0.20$ were included as fixed effects in the multivariable model. Explanatory variables that were checked in the univariable analysis included calf sex (male or female), arrival weight (low $=$ hipometer weight below the median arrival weight; high $=$ hipometer weight at or above the median arrival weight), and navel (yes or no). Biologically plausible 2 -way interactions were tested for significance. Manual backward stepwise elimination was used to reduce the model until all remaining variables were significant at the $\alpha \leq 0.05$ level. Treatment group was the only variable retained in both of the final models.

\section{RESULTS}

A total of 134 calves were enrolled into the study (MAB, $\mathrm{n}=72$; MEP, $\mathrm{n}=62$ ). One Jersey calf was enrolled but subsequently removed from analysis; therefore, the final study population consisted of 133 Holstein calves. Bull calves made up 72 and $37 \%$ of the treatment and control groups, respectively. Fourteen (9 MAB and 4 MEP) calves failed to produce adequate fecal specimens on d 0 and were therefore excluded from the d-0 analyses. Health scores were missed on a single day for 2 calves (one MAB and one MEP), so their total health scores were omitted from analysis. All calves had equivalent PCV and STP concentrations when sampled on d 0, 7, and 14 (Table 1). No calves died during the follow-up period.

Median fecal $\mathrm{pH}$ in MAB calves was lower compared with MEP calves on d $0(P=0.02$, Figure $1 \mathrm{~A})$ and higher than MEP calves on d $14(P=0.01$, Figure 1B). Fecal $\mathrm{pH}$ on $\mathrm{d} 5$ was not affected by treatment [MAB: 5.31, interquartile range $(\mathbf{I Q R})=5.09-5.87$; MEP: $5.29, \mathrm{IQR}=5.03-5.50 ; P=0.23]$. Fecal $\mathrm{pH}$ increased to a greater extent between $\mathrm{d} 0$ and 14 in treated compared with control calves $(P=0.0001$, Figure 2$)$. 

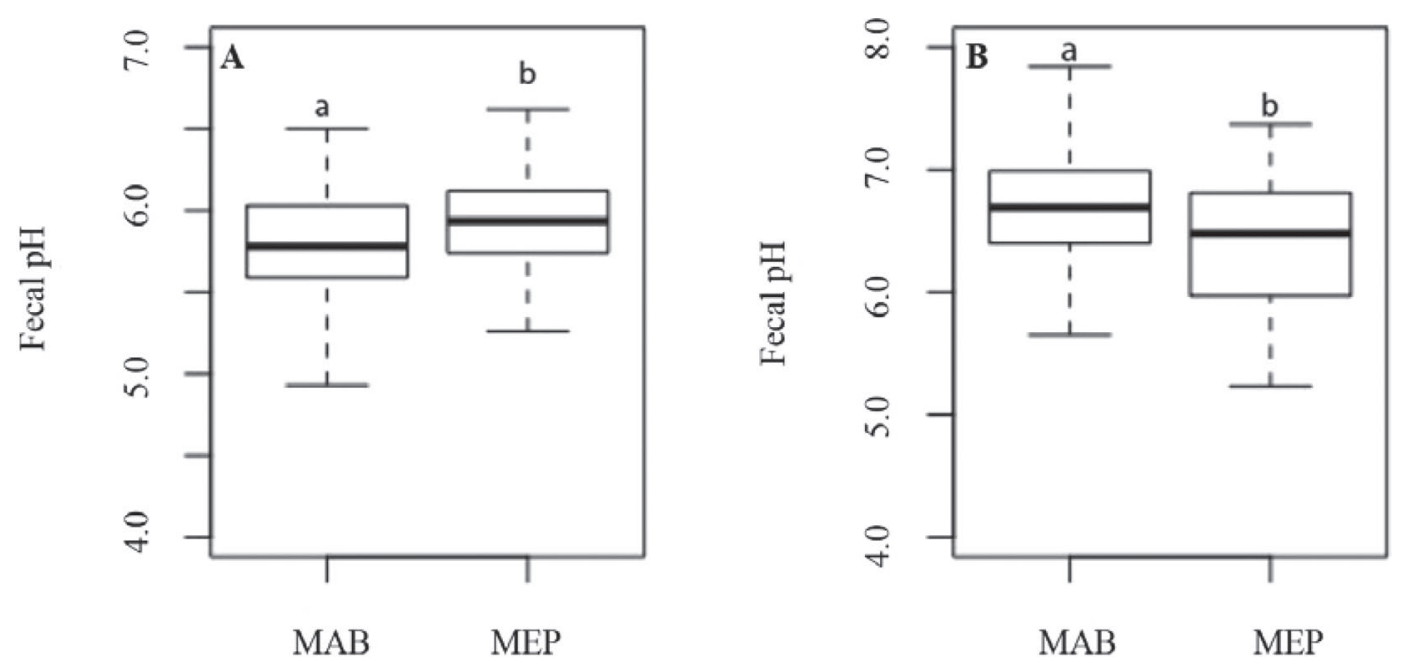

Figure 1. Box [median and interquartile range (IQR)] and whisker plots for fecal $\mathrm{pH}$ in 133 calves fed a daily dose of $0.96 \mathrm{~g}$ of egg yolk powder with (MAB) or without (MEP) anti-IL-10 antibodies in milk. (A) On d 0, median fecal pH in the MAB group (5.78, IQR = 5.59-6.01; $\mathrm{n}=62$ ) was lower than in the MEP group $(5.94, \mathrm{IQR}=5.74-6.12 ; \mathrm{n}=58)$. (B) On d 14, median fecal pH was higher in the MAB group (6.65, $\mathrm{IQR}=6.39-6.99 ; \mathrm{n}=71)$ compared with the MEP group $(6.52, \mathrm{IQR}=5.97-6.81 ; \mathrm{n}=62)$. Note the difference in y-axis scales. Group medians with different letters $(\mathrm{a}, \mathrm{b})$ are significantly different $(P \leq 0.05)$. Whiskers indicate the lowest and highest observations.

Overall, 26/71 (37\%) of MAB calves and 24/62 (39\%) of MEP calves were diagnosed with clinical respiratory disease during the study period $(P=0.80)$. Average daily respiratory score for the first $14 \mathrm{~d}$ did not differ between groups [MEP calves: $1.47(\mathrm{IQR}=1.1-1.67)$ vs. MAB calves: $1.33(\mathrm{IQR}=1.07-1.73)]$. However, compared with MEP, fewer MAB calves were diagnosed with respiratory disease on d 56 (MAB: 6/71, 8.5\%; MEP: $13 / 62,21.0 \% ; P=0.04)$ and treated with antibiotics (MAB: 7/71, 9.9\%; MEP: 16/62, 25.8\%; $P$ $=0.03)$ during the preweaned period compared with MEP calves (Figure 3). More specifically, the risk of respiratory disease at d 56 was lower in $\mathrm{MAB}$ calves compared with MEP calves [relative risk $(\mathbf{R R})=0.40$, $\mathrm{CI}=0.16-0.99]$. The risk of antibiotic treatment was lower in the MAB group compared with the MEP group $(\mathrm{RR}=0.38, \mathrm{CI}=0.17-0.88 ; P=0.01)$. Mean $( \pm \mathrm{SD})$ antibiotic cost per calf for the MEP and MAB

Table 1. Packed cell volume and serum total protein concentrations (mean \pm SD) on d 0, 7, and 14 after arrival to a calf ranch in preweaned dairy calves receiving a daily dose of $0.96 \mathrm{~g}$ of egg yolk powder with anti-IL-10 antibodies (MAB, $\mathrm{n}=71$ ) or without anti-IL-10 antibodies $(\mathrm{MEP}, \mathrm{n}=62)$

\begin{tabular}{lcc}
\hline Item & MAB & MEP \\
\hline Packed cell volume (\%) & $32 \pm 7$ & $31 \pm 5$ \\
d 0 & $33 \pm 5$ & $32 \pm 5$ \\
d 7 & $38 \pm 6$ & $38 \pm 6$ \\
d 14 & & \\
Serum total protein (mg/dL) & $7.2 \pm 0.8$ & $7.2 \pm 0.7$ \\
d 0 & $6.7 \pm 0.7$ & $6.8 \pm 0.6$ \\
d 7 & $6.5 \pm 0.6$ & $6.4 \pm 0.6$ \\
d 14 & & \\
\hline
\end{tabular}

groups were $\$ 3.78 \pm 7.93$ and $\$ 1.42 \pm 4.55$, respectively $(P=0.04)$. The costs of antibiotic treatments were systematically higher in the MEP group compared with the MAB group [MEP: median $\$ 0$ (IQR $=0-2.93)$ vs. MAB: median $\$ 0$ (IQR $=0-0) ; P=0.02]$.

The median cumulative total health score was numerically lower in calves in the MAB group $(49, \mathrm{IQR}=$ 42-61) versus the MEP group (52, IQR $=37-63 ; P=$ $0.94)$. A total of $63 / 71$ (89\%) of MAB calves and $56 / 62$ (90\%) of MEP calves developed diarrhea $(P=0.77)$. No difference was seen in the number of diarrhea days during the first $14 \mathrm{~d}$; both groups had a median of $3 \mathrm{~d}$ of diarrhea $(\mathrm{MAB} \mathrm{IQR}=2-5 ; \mathrm{MEP} \mathrm{IQR}=2-4 ; P=$ 0.98). A total of 30 calves had abnormal navel scores detected in at least one exam during the follow-up period; however, the proportion of abnormal navel scores was not different between groups [MAB: 13/71 (18\%); MEP: $17 / 62(27 \%) ; P=0.21$.

Upon arrival, raw hipometer-derived weights (median, IQR) were 43 (41-45) $\mathrm{kg}$ and $45(41-47) \mathrm{kg}$ in MAB and MEP calves, respectively $(P=0.29)$. Hipometer weights (median, IQR) were $73(70-77) \mathrm{kg}$ and $70(70-77) \mathrm{kg}$ on d 56 in MAB and MEP calves, respectively $(P=0.10)$. The differences in hipometer estimated weights between enrollment and d 56 were higher in the MAB group (median $=30 \mathrm{~kg}, \mathrm{IQR}=$ 28-33) compared with the MEP group (median $=27$ $\mathrm{kg}, \mathrm{IQR}=24-32 ; P=0.02$ ). The raw ADG in MAB calves was $0.75 \pm 0.11 \mathrm{~kg} / \mathrm{d}$, and the ADG in MEP calves was $0.78 \pm 0.11 \mathrm{~kg} / \mathrm{d}(P=0.11)$.

Multivariable linear regression models were also fit for the calf growth data. After controlling for navel 


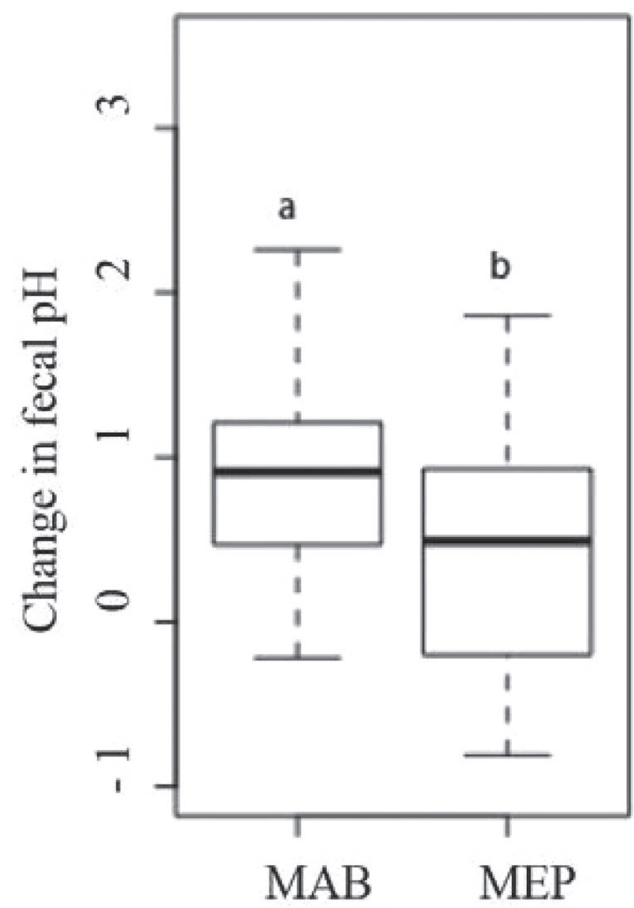

Figure 2. Box [median and interquartile range (IQR)] and whisker plots of median change in fecal $\mathrm{pH}$ between $\mathrm{d} 0$ and 14 in 133 preweaned dairy calves fed a daily dose of $0.96 \mathrm{~g}$ of egg yolk powder with (MAB) or without (MEP) anti-IL-10 antibodies. Fecal pH increased to a greater extent between $\mathrm{d} 0$ and 14 in MAB calves (change in fecal $\mathrm{pH}=0.91, \mathrm{IQR}=0.50$ to 1.21 ) compared with MEP calves (change in fecal $\mathrm{pH}=0.45, \mathrm{IQR}=-0.20$ to 0.93$)$. Group medians with different letters $(\mathrm{a}, \mathrm{b})$ are significantly different $(P \leq 0.05)$. Whiskers indicate the lowest and highest observations.

infection, hipometer weight (LSM $\pm \mathrm{SE}$ ) upon arrival was $43 \pm 0.6 \mathrm{~kg}$ in MAB and MEP calves $(P=0.23)$. Hipometer weight at $56 \mathrm{~d}$ was $73 \pm 0.6 \mathrm{~kg}$ and $71 \pm 0.6$ $\mathrm{kg}$ in MAB and MEP calves, respectively $(P=0.05)$ after controlling for arrival weight. Similarly, after controlling for arrival weight, the difference in hipometer weights between d 56 and arrival was $31 \pm 0.5 \mathrm{~kg}$ and $29 \pm 0.6 \mathrm{~kg}$ in MAB and MEP calves, respectively $(P$ $=0.02)$. Last, $\mathrm{ADG}$ was $0.74 \pm 0.01 \mathrm{~kg} / \mathrm{d}$ and $0.78 \pm$ $0.02 \mathrm{~kg} / \mathrm{d}$ in MAB and MEP calves, respectively $(P=$ 0.03 ) after controlling for calf sex, arrival weight, navel infection, and the interaction between arrival weight and navel infection.

Rotavirus was the predominant fecal pathogen detected on d 5, whereas C. parvum was the predominant pathogen on d 14 (Table 2). Salmonella Montevideo (n $=2)$ and Salmonella Newport $(\mathrm{n}=1)$ were cultured from a total of 3 calves, and fecal coronavirus was detected in 4 calves. Because of low prevalences, Salmonella spp. and coronavirus shedding were not analyzed any further. The cycle-threshold values (median; IQR)

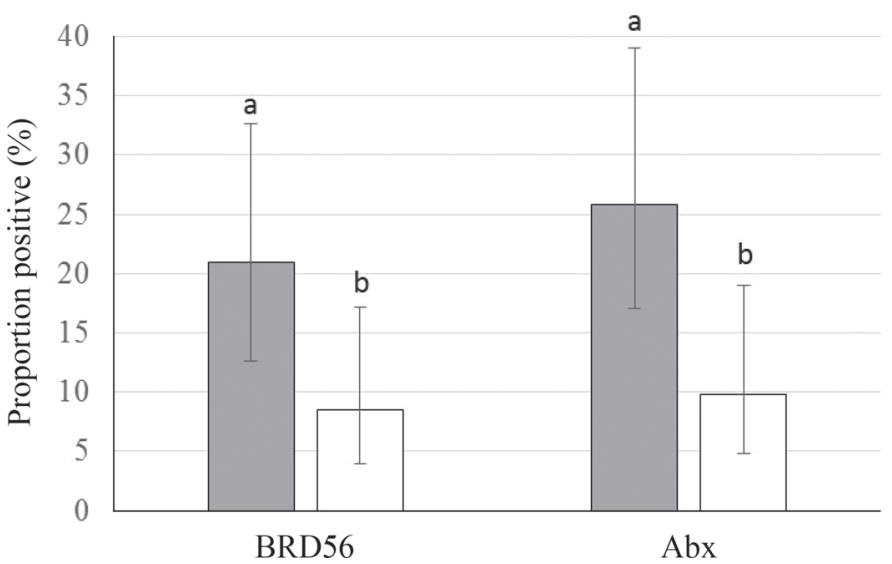

Figure 3. The proportion (95\% CI) of calves diagnosed with respiratory disease on d 56 (BRD56) and the proportion (95\% CI) of calves treated with at least one dose of antibiotic during the preweaning period $(\mathrm{Abx})$ are shown. Calves were fed a daily dose of $0.96 \mathrm{~g}$ of egg yolk powder with (MAB, $\mathrm{n}=71$; white bars) or without (MEP, $\mathrm{n}$ $=62$; gray bars) anti-IL-10 antibodies in milk. Groups with different letters $(\mathrm{a}, \mathrm{b})$ are significantly different $(P \leq 0.05)$.

for C. parvum and rotavirus are described in Table 3 . Overall risk of shedding rotavirus was greater for $\mathrm{MAB}$ calves compared with MEP calves $(\mathrm{RR}=1.38 ; 95 \% \mathrm{CI}$ $=1.10-1.81 ; P=0.02)$. The overall risk of shedding $C$. parvum was not different between groups $(\mathrm{RR}=1.10$; $95 \% \mathrm{CI}=0.92-1.32 ; P=0.63)$.

\section{DISCUSSION}

To the authors' knowledge, this is the first randomized, clinical trial showing that feeding anti-IL-10 egg yolk antibodies in pasteurized waste milk to dairy calves for $10 \mathrm{~d}$ was safe and feasible. Treated calves

Table 2. Overall prevalence of fecal pathogen shedding on $\mathrm{d} 5$ and 14 after arrival to a calf ranch in 133 preweaned calves receiving a daily dose of $0.96 \mathrm{~g}$ of egg yolk powder with anti-IL-10 antibodies (MAB, $\mathrm{n}$ $=71$ ) or without anti-IL-10 antibodies (MEP, $\mathrm{n}=62$ )

\begin{tabular}{llc}
\hline & \multicolumn{2}{c}{ Prevalence [no. (\%)] } \\
\cline { 2 - 3 } Fecal pathogen & \multicolumn{1}{c}{$\mathrm{d} 5$} & $\mathrm{~d} 14$ \\
\hline Rotavirus & $15(24)$ & $23(37)$ \\
MEP & $26(37)$ & $34(48)$ \\
MAB & 0 & $46(74)$ \\
Cryptosporidium parvum & $4(5.6)$ & $55(77)$ \\
MEP & $1(1.6)$ & $1(1.6)$ \\
Coronavirus & $2(2.8)$ & 0 \\
MEP & 0 & $2(3.2)$ \\
MAB & 0 & $1(1.4)$ \\
$\quad$ MElmonella spp. & 0 & \\
MAB & &
\end{tabular}


maintained fecal $\mathrm{pH}$, had a greater change in frame size between enrollment and d 56 according to hipometer measures, had less respiratory disease at weaning and fewer antibiotic treatments, and caused less cost to the producer under the conditions of this trial.

Fecal $\mathrm{pH}$ in the calves in this study fell into the expected range at enrollment and acidified with age as previously described (Shimomura and Sato, 2006). The $\mathrm{MAB}$ group showed less fecal acidification over time than the MEP calves, suggesting that the immature microflora in the colon of treated calves might produce less lactate or more VFA (Shimomura and Sato, 2006; Sato, 2010). Lower colonic $\mathrm{pH}$ has been associated with colonic epithelial damage as well as osmotic diarrhea (Shimomura and Sato, 2006; Sato, 2010). Regarding young dairy calves, C. parvum infection is associated with malabsorption of carbohydrates, which may be responsible for increased lactate fermentation and fecal acidification. The higher fecal $\mathrm{pH}$ in the MAB group following enrollment may provide evidence of improved small intestinal absorption of carbohydrates in this group.

The reduced risk of respiratory disease at d 56 as well as antibiotic treatment in the MAB group was unexpected. Although it is possible that this finding is spurious, others have shown an increased risk of BRD later in the preweaning period in calves that have had earlier disease problems such as NCD in the first $2 \mathrm{wk}$ of life (Windeyer et al., 2014). It is possible that stabilizing fecal $\mathrm{pH}$ in very young calves, as demonstrated in the current study, or other unmeasured changes in the gastrointestinal function, had some effect on the development of clinical respiratory disease later in the preweaning period. The mechanism of improved respiratory health seen after improving gastrointestinal health is unknown; however, literature suggests pulmonary-intestinal cross-talk given the similar epithelial surfaces and mucosa-associated lymphoid tissue (Keely

Table 3. Cycle-threshold values ${ }^{1}$ for fecal pathogens detected in 134 preweaned dairy calves on d 5 and 14 after arrival to a calf ranch. Calves received a daily dose of $0.96 \mathrm{~g}$ of egg yolk powder with antiIL-10 antibodies (MAB, $\mathrm{n}=71$ ) or without anti-IL-10 antibodies $(\mathrm{MEP}, \mathrm{n}=62)$

\begin{tabular}{lccc}
\hline Pathogen & MEP & MAB & $P$-value \\
\hline Cryptosporidium parvum & $41(41-41)$ & $41(41-41)$ & 0.06 \\
$\quad$ d 5 & $34(32-41)$ & $35(34-40)$ & 0.08 \\
d 14 & $41(41-41)$ & $41(32-41)$ & 0.07 \\
Rotavirus & $41(35-41)$ & $41(34-41)$ & 0.22 \\
$\quad$ d 5 & & \\
d 14
\end{tabular}

${ }^{1}$ Median (interquartile range). et al., 2012). Similar shared immune components and overlapping pathological changes of inflammation have been noted in human respiratory and intestinal mucosal disease (Keely et al., 2012; McGhee and Fujihashi, 2012). Although antibiotic administration was primarily for treatment of respiratory disease, farm personnel responsible for treatment decisions were blind to treatment group and where not made aware of daily health scores. Therefore, bias at the level of farm personnel should not be driving these observed differences.

We did not detect a significant difference in the level of C. parvum shedding or the risk of shedding during this study. Previous research has shown elimination of C. parvum infection in IL-10 knockout mice and reduced oocyst shedding in Eimeria-infected chickens (Campbell et al., 2002; Sand et al., 2016). Additional research is warranted before completely ruling out antiIL-10 antibodies as a potential preventative against $C$. parvum.

We also did not detect a significant difference in the median level of rotavirus shedding between groups (based on cycle-threshold values); however, risk of rotavirus shedding in the MAB group was increased at $d$ 14. This might suggest that the binding of IL-10 may negatively affect the immune response specific to rotavirus or reduce infectivity with increased passage of the virus.

The hipometer estimated weight benefit, which was seen in the difference between measurements taken at d 56 and enrollment in MAB calves, may indicate improved stature or frame size rather than weight. Improved stature at weaning is of importance to future performance of dairy calves; however, this finding should be interpreted with caution because agreement of the hipometer-estimated and digital weights has been questioned in calves less than 3 mo of age (Dingwell et al., 2006).

This study was limited in sample size because calf numbers were dependent on calf-raiser management practices, including daily variation in numbers, age, breed, and sex of calves delivered from source farms, and limitations on the duration of the calf enrollment period. Researchers should use results from this study to determine sample size in future studies. These studies are needed to elucidate the mechanisms of improved fecal $\mathrm{pH}$, reduced respiratory disease, increased hipometer measurements, and the long-term implications of these changes. Reduced antibiotic use in preweaned calves as suggested in this study is of substantive economic, welfare, and potential consumer benefit. Treatment dose and duration should be explored to further validate the effect of anti-IL-10 antibody on respiratory health, calf growth, and fecal pathogen shedding. 


\section{CONCLUSIONS}

Feeding anti-IL-10 egg yolk antibodies in pasteurized milk upon arrival to a calf ranch did not change the proportion of calves testing positive for C. parvum. Despite this finding, treated calves maintained fecal $\mathrm{pH}$, developed larger frames, and were less likely to receive antibiotics and be diagnosed with respiratory disease at weaning, suggesting some benefit of feeding anti-IL-10 antibodies. Future research is needed to confirm that that these beneficial differences are repeatable and are the result of feeding anti-IL-10. Additional studies should also investigate different dosing strategies and look closer at the effect of anti-IL-10 egg yolk antibodies on respiratory health.

\section{ACKNOWLEDGMENTS}

The authors thank the veterinary students who assisted in data collection, the calf-raising facility for participation, and DeLaval (Kansas City, MO) for providing funding.

\section{REFERENCES}

Berge, A. C., D. A. Moore, and W. M. Sischo. 2006. Field trial evaluating the influence of prophylactic and therapeutic antimicrobial administration on antimicrobial resistance of fecal Escherichia coli in dairy calves. Appl. Environ. Microbiol. 72:3872-3878.

Campbell, L. D., J. N. Stewart, and J. R. Mead. 2002. Susceptibility to Cryptosporidium parvum infections in cytokine- and chemokineresistant knockout mice. J. Parasitol. 88:1014-1016.

Cho, Y. I., W. I. Kim, S. Lui, J. M. Kinyon, and K. J. Yoon. 2010 Development of a panel of multiplex real-time polymerase chain reaction assays for simultaneous detection of major agents causing calf diarrhea in feces. J. Vet. Diagn. Invest. 22:509-517.

Cook, M. E., and D. L. Trott. 2010. IgY-Immune component of eggs as a source of passive immunity for animals and humans. Worlds Poult. Sci. J. 66:215-225.

Cramer, M. C., and A. L. Stanton. 2015. Associations between health status and the probability of approaching a novel object or stationary human in preweaned group-housed dairy calves. J. Dairy Sci. 98:7298-7308

Dickinson Gibbons, J., and S. Chakraborti. 2003. Nonparametric Statistical Inferences. 4th ed. Marcel Dekker Inc., New York, NY.

Dingwell, R. T., M. M. Wallace, C. J. McLaren, C. F. Leslie, and K. E. Leslie. 2006. An evaluation of two indirect methods of estimating body weight in Holstein calves and heifers. J. Dairy Sci. 89:3992-3998.

Diraviyam, T., B. Zhao, Y. Wang, R. Schade, A. Michael, and X. Zhang. 2014. Effect of chicken egg yolk antibodies (IgY) against diarrhea in domesticated animals: A systematic review and metaanalysis. PLoS One 9:e97716.
Keely, S., N. J. Talley, and P. M. Hansbro. 2012. Pulmonary-intestinal cross-talk in mucosal inflammatory disease. Mucosal Immunol. $5: 7-18$.

Lee, J., H. E. Kang, and J. Woo. 2012. Stability of orally administered immunoglobulins in the gastrointestinal tract. J. Immunol. Methods $384: 143-147$.

McGhee, J. R., and K. Fujihashi. 2012. Inside the mucosal immune system. PLoS Biol. 10:e1001397.

McGuirk, S. M. 2008. Disease management of dairy calves and heifers. Vet. Clin. North Am. Food Anim. Pract. 24:139-153.

McGuirk, S. M., and S. F. Peek. 2014. Timely diagnosis of dairy calf respiratory disease using a standardized scoring system. Anim. Health Res. Rev. 15:145-147.

Mine, Y., and J. Kovacs-Nolan. 2002. Chicken egg yolk antibodies as therapeutics in enteric infectious disease: A review. J. Med. Food $5: 159-169$.

Nydam, D. V., and H. O. Mohammed. 2005. Quantitative risk assessment of Cryptosporidium species infection in dairy calves. J. Dairy Sci. 88:3932-3943.

Sand, J. M., M. K. Arendt, A. Repasy, G. Deniz, and M. E. Cook. 2016. Oral antibody to interleukin-10 reduces growth rate depression due to Eimeria spp. infection in broiler chickens. Poult. Sci. 95:439-446.

Sato, H. 2010. Fecal trimethylamine, lactate, and volatile fatty acid concentrations and their relationships with diarrhea in newborn dairy calves. J. Vet. Med. Sci. 72:1551-1555.

Shimomura, Y., and H. Sato. 2006. Fecal D- and L-lactate, succinate, and volatile fatty acid levels in young dairy calves. J. Vet. Med. Sci. 68:973-977.

Smith, G. 2015. Antimicrobial decision making for enteric diseases of cattle. Vet. Clin. North Am. Food Anim. Pract. 31:47-60.

Vega, C., M. Bok, P. Chacana, L. Saif, F. Fernandez, and V. Parreno. 2011. Egg yolk IgY: Protection against rotavirus induced diarrhea and modulatory effect on the systemic and mucosal antibody responses in newborn calves. Vet. Immunol. Immunopathol. 142:156-169.

Weaver, D. M., J. W. Tyler, D. C. Van Metre, D. E. Hostetler, and G. M. Barrington. 2000. Passive transfer of colostral immunoglobulins in calves. J. Vet. Intern. Med. 14:569-577.

Windeyer, M. C., K. E. Leslie, S. M. Godden, D. C. Hodgins, K. D. Lissemore, and S. J. LeBlanc. 2014. Factors associated with morbidity, mortality and growth of dairy calves up to 3 months of age. Prev. Vet. Med. 113:231-240.

Wyatt, C. R., W. J. Barrett, E. J. Brackett, D. A. Schaefer, and M. W. Riggs. 2002. Association of IL-10 expression by mucosal lymphocytes with increased expression of Cryptosporidium parvum epitopes in infected epithelium. J. Parasitol. 88:281-286.

Wyatt, C. R., E. J. Brackett, and J. Savidge. 2001. Evidence for the emergence of a Type-1-like immune response in intestinal mucosa of calves recovering from cryptosporidiosis. J. Parasitol. 87:90-95.

Wyatt, C. R., M. W. Riggs, and R. Fayer. 2010. Cryptosporidiosis in neonatal calves. Vet. Clin. North Am. Food Anim. Pract. 26:89103.

Yokoyama, H., R. C. Peralta, K. Umeda, T. Hashi, F. C. Jr. Icatlo, M. Kuroki, Y. Ikemori, and Y. Kodama. 1998. Prevention of fatal salmonellosis in neonatal calves, using orally administered chicken egg yolk Salmonella-specific antibodies. Am. J. Vet. Res. 59:416420. 